\title{
Nominalism, Trivialist Platonism and Benacerraf's dilemma
}

DOI:

10.1093/analys/anu038

\section{Document Version}

Accepted author manuscript

Link to publication record in Manchester Research Explorer

\section{Citation for published version (APA):}

Daly, C., \& Liggins, D. (2014). Nominalism, Trivialist Platonism and Benacerraf's dilemma. Analysis, 74(2), 224231. https://doi.org/10.1093/analys/anu038

\section{Published in:}

Analysis

\section{Citing this paper}

Please note that where the full-text provided on Manchester Research Explorer is the Author Accepted Manuscript or Proof version this may differ from the final Published version. If citing, it is advised that you check and use the publisher's definitive version.

\section{General rights}

Copyright and moral rights for the publications made accessible in the Research Explorer are retained by the authors and/or other copyright owners and it is a condition of accessing publications that users recognise and abide by the legal requirements associated with these rights.

\section{Takedown policy}

If you believe that this document breaches copyright please refer to the University of Manchester's Takedown Procedures [http://man.ac.uk/04Y6Bo] or contact uml.scholarlycommunications@manchester.ac.uk providing relevant details, so we can investigate your claim.

\section{OPEN ACCESS}




\section{Nominalism, Trivialist Platonism, and Benacerraf's Dilemma \\ CHRIS DALY AND DAVID LIGGINS}

[Published in Analysis 74.2 (2014): 224-231]

\section{Introduction}

In his stimulating new book The Construction of Logical Space, Agustín Rayo clarifies 'just is'statements, such as:

(SIBLING) For Susan to be a sibling just is for her to share a parent with someone else.

and

(WATER) For the glass to be filled with water just is for it to be filled with $\mathrm{H}_{2} \mathrm{O}$. (3)

Rayo's book also offers a new account of mathematics, in which 'just is' statements play a starring role. Rayo calls the view Trivialist Platonism; let us call it 'TP' for short. Our purpose here is to evaluate TP. We will argue that Rayo's case for TP does not succeed.

To begin with, we introduce TP. We then take issue with Rayo's main argument for TP (section 3) and his claim that TP overcomes Benacerraf's dilemma (section 4). Our conclusion is that Rayo has not shown that TP has any advantage over nominalism. (References are to Rayo 2013, and italics are in the original, unless otherwise stated.)

\section{Trivialist Platonism}

Suppose that it is the case that $\phi$ and also the case that $\psi$. Consider the claim:

(JUST IS) For it to be the case that $\phi$ just is for it to be the case that $\psi$.

According to Rayo, JUST Is implies that ' $\phi$ ' and ' $\psi$ ' are 'full and accurate descriptions of the same features of reality' (5); that there is 'no difference' between its being the case that $\phi$ and its being the case that $\psi(5)$; and that the following is metaphysically necessary: $\phi$ iff $\psi$ (where 'iff' is the material biconditional) (55). (See chapter 2 for Rayo's elucidation of the 'just is' operator.) We do not take issue with any of these claims. Since the 'just is' operator is used by others more often than it is explained, we applaud Rayo for his careful clarification.

According to TP, 
(DINOSAURS) For the number of dinosaurs to be Zero just is for there to be no dinosaurs.

As Rayo would put it, 'The number of dinosaurs is Zero' and 'There are no dinosaurs' are 'full and accurate descriptions of the same features of reality'; there is 'no difference' between the number of dinosaurs being Zero and there being no dinosaurs; the number of dinosaurs being Zero is a metaphysically necessary and sufficient condition for there being no dinosaurs.

More generally, TP implies every instance of the following schema:

(NUMBERS) For the number of the Fs to be $n$ just is for there to be exactly $n$ Fs.

TP is distinct from but resembles the neo-Fregean variety of platonism (see section 3.2 for a comparison).

Rayo claims that we should believe 'just is'-statements on the basis of how well they combine with our existing theories to provide a 'fruitful tool for scientific or philosophical inquiry' (viii). Rayo points out that believing a 'just is'-statement reduces the scenarios one has to rule out: if we believe JUST IS, then we rule out scenarios in which $\phi$ but not $\psi$, and scenarios in which $\psi$ but not $\phi$ (viii; here Rayo writes of 'possibilities' rather than 'scenarios'). This allegedly brings the benefit that we need not answer questions such as 'Why is it the case that $\phi$ but not $\psi$ ?'. But it also brings a cost: we can no longer offer explanations that appeal to it being the case that $\phi$ but not $\psi$ (or $\psi$ but not $\phi)$. We must decide which 'just is'-statements to believe by weighing these costs and benefits (see 18-21, 37-8).

According to Rayo, the benefits of accepting NUMBERs far exceed the costs (74). For instance, the acceptance of DINOSAURS blocks 'awkward questions' (to use Rayo's phrase: xii, 9, 21-22, 33) about how the non-existence of dinosaurs can be correlated with Zero numbering the dinosaurs: they are just the same thing. What about the costs? By accepting NumBers we lose the ability to appeal to scenarios in which there are no numbers. But it seems to Rayo that 'this is not much of a price to pay, since the availability of such scenarios is not very likely to lead to fruitful theorizing' (74).

\section{The alleged unfruitfulness of nominalism}

Let us call the view that there are numbers and other mathematical objects 'platonism', and let us call its negation 'nominalism'. We have seen that in the course of arguing for TP, Rayo claims that nominalist theories - accounts of mathematics according to which there are no mathematical 
objects - probably incur a serious theoretical cost, in that they are unlikely to be theoretically fruitful. We have two comments in response.

The first is a clarification: 'fruitfulness' must be understood correctly. In one sense of 'fruitfulness', even false theories can be theoretically fruitful, in that they can inspire philosophers to make important distinctions, propose alterative theories, and, more generally, lead to deeper work on the topic. Whatever philosophers think about nominalism, they would concede that research by Field $(1980,1989)$ and others have had these results. So fruitfulness must be understood in some other way for Rayo's argument to succeed.

Our second comment concerns Rayo's argument that nominalist theories are unlikely to be theoretically fruitful in the relevant sense. In arguing for his preferred version of platonism, Rayo claims that nominalist theories do not offer the best net balance of theoretical virtue over theoretical cost. But to establish platonism, this is precisely what needs to be shown. And establishing platonism is part of what needs to be done to establish TP. Rayo's argument is therefore incomplete. He cannot simply assert that nominalist alternatives to TP are inferior, but must argue for that claim. Moreover, nominalists will contradict him: they will maintain that nominalist theories are, all things considered, more theoretically virtuous than any platonist theory so far offered; and they will argue that - unlike platonist theories - nominalist accounts of mathematics are ontologically parsimonious and epistemologically solvent. The challenge to Rayo is to explain why this evaluation is wrong, by telling us what makes nominalist theories inferior to platonist ones. In the absence of such an argument, Rayo's argument for TP cannot succeed.

It is likely that Rayo will retort that TP is epistemologically solvent. Accordingly, we will now examine his comments on the epistemology of mathematics.

\section{Rayo on Benacerraf's dilemma}

Rayo's epistemology of mathematics appeals to his notion of triviality, so we must first introduce that notion. It is important to be clear that Rayo is using the word 'trivial' in a technical sense. To define 'trivial', Rayo uses the notion of metaphysical consistency. Rayo claims that a sentence is metaphysically consistent just in case it describes a metaphysically possible scenario (52); a sentence is metaphysically inconsistent just in case it describes a metaphysically impossible scenario. Rayo says that a sentence has trivial truth-conditions 'just in case its negation is metaphysically inconsistent' (53). So a sentence has trivial truth-conditions just in case it describes a metaphysically necessary scenario. 
For instance, that the glass is filled with water iff it is filled with $\mathrm{H}_{2} \mathrm{O}$ is metaphysically necessary, SO WATER describes a metaphysically necessary scenario. Therefore WATER has trivial truth-conditions. In fact, on Rayo's view, every true 'just is'-statement has trivial truth-conditions (38). That follows from the fact that JUST Is implies the metaphysical necessity of ' $\phi$ iff $\psi$ '. Accordingly, Rayo holds that every instance of NUMBERS has trivial truth-conditions.

Rayo also claims that 'There are numbers' has trivial truth conditions. To support his claim, Rayo argues as follows. Suppose that there were no numbers. Then (by NUMBERS) the number of numbers would be Zero. But then there would be a number after all, namely, Zero. Reductio (75; a similar argument appears at Tennant 1997: 321). Furthermore, Rayo claims that every truth of pure mathematics has trivial truth-conditions (74). His semantics for arithmetical sentences implies that each sentence of pure arithmetic has trivial truth-conditions (section 3.3).

Section 4.1 of Rayo's book is devoted to Benacerraf's well-known dilemma for philosophers of mathematics. One horn of the dilemma is that if we interpret mathematical sentences in the obvious way, as claims about mathematical objects, then we must believe in the existence of such things. We are then faced with the problem of explaining how we gain mathematical knowledge, since mathematical objects, if they exist, are abstract, and thereby 'beyond the reach of the better understood means of human cognition' (Benacerraf 1973: 667). The other horn is that if we interpret mathematical sentences some other way, we have the difficult task of reconciling this interpretation with our interpretation of non-mathematical claims.

Rayo claims that TP 'delivers a straightforward answer' to Benacerraf's dilemma (99). His argument is based on the claim that TP assigns trivial truth-conditions to true sentences of pure mathematics:

As directed towards ... someone who thinks that the truths of mathematics have non-trivial truth-conditions ... Benacerraf's Dilemma has force, at least on a suitably cleaned up version of the argument .... For if the existence of numbers is non-trivial - if God would have had to do something extra to make sure they were in place - then there is room for asking how one could ever check whether the world does indeed contain numbers....

As directed towards a trivialist, on the other hand, the dilemma has little force. For, according to the trivialist, nothing is required of the world in order for the truth-conditions of a truth of pure mathematics to be satisfied. That means, in particular, that there is no need to check whether any requirements have been met in order to determine whether the truthconditions of a truth of pure mathematics are satisfied. Once one gets clear about the 
sentence's truth-conditions - clear enough to know they are trivial - one has done all that needs to be done to determine that the sentence is true. (98)

In other words, TP overcomes the first horn of Benacerraf's dilemma by explaining how we come to know about abstract mathematical objects. Benacerraf's demand for an account of our cognitive access to these objects is met by the observation that mathematical truths have trivial truthconditions.

We believe that TP fails to blunt the first horn of Benacerraf's dilemma. In short, Rayo's argument relies on conflating metaphysical with epistemic possibility. ${ }^{1}$

Worries about such conflation are raised by the first page of the book. Here Rayo claims, without argument: 'To set forth a statement is to make a distinction amongst ways for the world to be, and to single out one side of this distinction [as the way the world actually is]' (vii; see also 57-8). It is clear from the context that when Rayo writes 'ways for the world to be', he is thinking of metaphysical possibilities. Rayo's claim, then, is that an assertion locates the world within the space of metaphysical possibilities. We do not find this at all plausible. It seems clear that one can assert 'Water is $\mathrm{H}_{2} \mathrm{O}_{2}$ ', 'Hesperus is rising but Phosphorus is not', and other metaphysically impossible falsehoods. On account of the metaphysical impossibility of their contents, these assertions do not locate the world within the space of metaphysical possibilities. Rather, they locate the world within epistemic space: they make a distinction amongst ways the world might be thought to be, and single out a side of this distinction as the way the world actually is.

Perhaps there is a sense of 'assert' in which to assert a sentence is merely to utter a sentence. ${ }^{2}$ But there seems to be no reason to think that the only sense in which one can assert the above examples is merely to utter them. In another sense of 'assertion', if one asserts a sentence, one is not merely uttering it but using it to make a claim. What seems to be the default view is that one can assert the above examples in this second sense, and we have seen no reason to think otherwise. Furthermore, the default view finds independent support. The Babylonians used (the Akkadian equivalent of) 'Hesperus is rising but Phosphorus is not' to express their belief that Hesperus is rising but Phosphorus is not, and the characteristic way of using a sentence to express one's belief in its

\footnotetext{
${ }^{1}$ As the quotation makes clear, Rayo assumes that realising that a given sentence expresses something trivial (in his sense) is a discovery. He thereby rejects the view that finding that a given sentence expresses a tautology or a metaphysical necessity may seem like a discovery but is nothing of the sort. According to the view in question, in such a case nothing new has been learned and the impression of a discovery was mistaken. We are grateful to the referee for drawing attention to this view.

${ }^{2}$ We are grateful to the referee for making this suggestion.
} 
content is to assert that sentence. Again, today we assert the negations of the above metaphysically impossible falsehoods. Yet if we can assert the negations of those sentences, it seems that people can assert those sentences themselves. Philosophers debate the truth-values of such sentences as 'An organism's origin is essential to it'. Some of the disputants assert it; others assert its negation. One or other of these parties is making an assertion which does not locate the actual world within the space of metaphysical possibilities.

In the same vein, Rayo writes: 'Going beyond metaphysical possibility is not a matter of going beyond a given limit of strictness: it is a matter of lapsing into absurdity' (49). For instance, the claim that there is something that is water but not $\mathrm{H}_{2} \mathrm{O}$ is absurd in Rayo's sense. Talk of 'absurdity' suggests that absurd claims can easily be disproved, but that is not the case, as this example shows. Rayo (53) admits this, but he immediately goes on to write: 'Where a sentence has trivial truthconditions, I will say that nothing would be required of the world in order for its truth-conditions to be satisfied. (That involves ignoring absurd scenarios, but absurd scenarios are rightfully ignored.)' Rayo's phrase 'rightfully ignored' suffers from the same metaphysical/epistemic ambiguity. In a metaphysical sense, a scenario is rightfully ignored if it does not obtain. In an epistemic sense, however, what is rightfully ignored depends on the evidence one has. If one possessed evidence apparently proving that water is $\mathrm{H}_{2} \mathrm{O}_{2}$, then it would be epistemically irresponsible to ignore scenarios in which water is $\mathrm{H}_{2} \mathrm{O}_{2}$.

To describe a piece of knowledge as 'trivial' often implies that it is easy to acquire. So the phrase 'trivialist platonism' suggests that mathematical knowledge is knowledge of trivialities, and therefore easily acquired. But that line of thought confuses different senses of 'trivial'. In the sense Rayo is using, knowledge of trivialities is knowledge of metaphysical necessities. But to tell us that a piece of knowledge is knowledge of a metaphysically necessary truth does not tell us anything about how the knowledge is gained. The modal status of the knowledge's content is silent concerning the epistemology of its acquisition. To think otherwise would be to conflate metaphysical with epistemic modalities. (When Rayo claims that 'everyone agrees that trivial truth-conditions are satisfied' (38), he appears to be conflating the two senses of 'trivial'.)

To make the point more vivid, recall that Rayo is committed to holding that every true 'just is' statement has trivial truth-conditions. Let us therefore repeat the passage above with the example of (WATER) in mind.

According to the trivialist, nothing is required of the world in order for the truth-conditions of a truth of analytical chemistry to be satisfied. That means, in particular, that there is no need to 
check whether any requirements have been met in order to determine whether 'For the glass to be filled with water just is for it to be filled with $\mathrm{H}_{2} \mathrm{O}^{\prime}$ is true. Once one gets clear about the sentence's truth-conditions - clear enough to know they are trivial - one has done all that needs to be done to determine that the sentence is true.

This modification reveals that all the epistemic work is packed into 'getting clear about the sentence's truth-conditions'. That phrase could naturally be taken to mean something that is implied by understanding the sentence, but Rayo must have something much more demanding in mind, such that people were not clear about the truth-conditions of sentences mentioning water until they knew the chemical composition of water. This reveals that the appeal to triviality is a red herring: we could tell just the same story about knowledge of sentences which have metaphysically contingent truth-conditions. Appeal to triviality does not help explain how we come to learn the truths of analytical chemistry. Even if 'For the glass to be filled with water just is for it to be filled with $\mathrm{H}_{2} \mathrm{O}^{\prime}$ is a triviality, there still remains a substantial epistemic task: in order to know that the sentence is true, we still have to discover that it is a triviality.

In just the same way, appeal to triviality does not help explain how we come to know the truths of pure mathematics. In particular, Rayo's appeal to triviality does nothing to remove Benacerraf's puzzle of our cognitive engagement with abstract objects. Benacerraf's challenge was to explain, if platonism is true, how we know that 'The number of dinosaurs is Zero' is true. Let's grant Rayo that 'The number of dinosaurs is Zero' has trivial truth-conditions and so 'nothing would be required of the world in order for its truth-conditions to be satisfied'. Let's also grant Rayo that knowledge of the triviality of this sentence's truth-conditions is sufficient for knowledge of its truth. We still face the question: how do we know that it has trivial truth-conditions? So even if we concede that the sentence has trivial truth-conditions, that does nothing to remove Benacerraf's puzzle.

Rayo might respond by withdrawing his assertion that TP provides a 'straightforward answer' to Benacerraf. He might claim that, although his appeal to triviality does not furnish a complete solution to Benacerraf's puzzle, it does furnish a partial solution: the puzzle of our cognitive engagement with abstract objects has been reduced to the puzzle of finding out that the truthconditions of mathematical sentences are trivial.

There are two problems with this response. To see the first, recall that Rayo is using the term 'truth-conditions' in an unusual way, such that establishing the triviality of the truth-conditions of sentences about water required substantial empirical inquiry. Rayo has not identified the counterpart of this task in the mathematical case: he has not explained how we are to establish that 
mathematical sentences do have trivial truth-conditions. He has therefore given us no reason to think that this task is any easier than the initial task of solving Benacerraf's puzzle. For all Rayo has said, his appeal to triviality makes the puzzle harder.

To see the second problem, notice that we do not learn the truths of analytical chemistry by learning that certain sentences have trivial truth-conditions. Rayo's concept of triviality is a technical philosophical concept introduced in his book: it is not a staple of chemical research. Just the same carries over to the mathematical case: we do not learn mathematical truths by learning that certain sentences have trivial truth-conditions. So even if Rayo can demonstrate that mathematical sentences have trivial truth-conditions, that does not explain how those who have not read his demonstration gain their mathematical knowledge. But Benacerraf's challenge was not to provide a possible way for people to gain mathematical knowledge, but, rather, to explain how people actually gain mathematical knowledge if platonism is true. So invoking the concept of triviality does not help respond to Benacerraf's challenge. ${ }^{3}$

After discussing Benacerraf's dilemma, Rayo goes on to present a Stalnakerian theory of the nature of 'cognitive accomplishment' in mathematics. We note that this theory is not intended to and does not - explain how we make cognitive engagement with abstract objects.

To conclude: Rayo fails to show that his preferred version of platonism has the advantages he claims for it. His arguments leave nominalism untouched. ${ }^{4}$

\author{
School of Social Sciences \\ University of Manchester \\ Oxford Road \\ Manchester \\ M13 9PL \\ david.liggins@manchester.ac.uk \\ christopher.daly@manchester.ac.uk
}

\title{
References
}

\footnotetext{
${ }^{3}$ In this respect, Rayo resembles his neo-Fregean predecessors: MacBride (2002: 129-30) points out that the neoFregeans' concern is to provide a 'reconstruction' of mathematical knowledge - an account of how it is possible to acquire mathematical knowledge - rather than an account of actual mathematical knowledge.

${ }^{4}$ We would like to thank Matti Eklund, Agustín Rayo, and an anonymous referee. Thanks also to the Philosophy Senior Seminar at the University of Glasgow.
} 
Benacerraf, P. 1973. Mathematical truth. Journal of Philosophy 70: 661-679.

Field, H. 1980. Science without Numbers: A Defence of Nominalism. Oxford: Blackwell.

Field, H. 1989. Realism, Mathematics and Modality. Oxford: Blackwell.

MacBride, F. 2002. Could nothing matter? Analysis 62: 125-35.

Rayo, A. 2013. The Construction of Logical Space. Oxford: Oxford University Press.

Tennant, N. 1997. On the necessary existence of numbers. Noûs 31: 307-336. 
Abstract. In his stimulating new book The Construction of Logical Space, Agustín Rayo offers a new account of mathematics, which he calls 'Trivialist Platonism'. In this paper, we take issue with Rayo's case for Trivialist Platonism and his claim that the view overcomes Benacerraf's dilemma. Our conclusion is that Rayo has not shown that Trivialist Platonism has any advantage over nominalism.

Keywords: platonism, nominalism, Benacerraf's dilemma, 'just is' statements, trivialism 